\title{
STANDARDIZATION OF ANTICONVULSANT POLYHERBAL FORMULATION BY PHARMACOGNOSTICAL, DNA FINGERPRINTING AND HIGH-PERFORMANCE THIN LAYER CHROMATOGRAPHY COMBINED WITH CHEMOMETRICS
}

\author{
HETAL JANANI, JAYANTA KUMAR MAJI*, ASHISH VERMA \\ Department of Pharmaceutical Chemistry, Gujarat Ayurveda University, India \\ Email: jkmaji67@gmail.com
}

Received: 23 Sep 2016, Revised and Accepted: 15 Nov 2016

\begin{abstract}
Objective: The combination between the stem bark powder of Chirabilva and Veerataru is used ethno folklore for the management of anticonvulsion by tribal people. To standardise the evidently used polyherbal formulation in a systemic way for supporting the identity, quality, purity, safety and efficacy concern with modern technique.

Methods: Microscopic anatomical examination and powder microscopy were performed fresh and dried plant materials respectively. The compound polyherbal formulation is processed by organoleptic characterization, macro-microscopic evaluation, physicochemical, phytochemical testing, DNA fingerprinting and high-performance thin-layer chromatography (HPTLC) profiling employing a standard methodology. Chromatographic fingerprinting after visualisation the data are exploited by multivariate chemometric technique.

Results: Results of the experiment provided diagnostic characteristics to identify quality and purity and standardise the polyherbal formulation along with respective ingredients. The RAPD analysis of Dichrostachys cinerea and Holoptelea integrin folia showed some similar bands at the same base pair indicate the presence of genetical identity may take into consideration of the control the ingredients. HPTLC technique utilised to distinguish the ingredient and polyherbal formulation based on the presence or absence of certain target phytochemical (flavonoid, polyphenol, etc.) constituents, manifested as peaks or bands from the chemical fingerprint profiles. Visualized chromatographic profile of polyherbal formulation along with its constituents applying the multivariate chemometric technique is easily discriminated of respective retardation factor in principal component score space.
\end{abstract}

Conclusion: The findings from this study will provide systemic evaluation for this anticonvulsant formulation and also serve as a master document to control the quality of polyherbal formulation.

Keywords: Anticonvulsant, Chemometrics, DNA fingerprinting, HPTLC, Pharmacognosy

(C) 2016 The Authors. Published by Innovare Academic Sciences Pvt Ltd. This is an open access article under the CC BY license (http://creativecommons.org/licenses/by/4.0/) DOI: http://dx.doi.org/10.22159/ijcpr.2017v9i1.16606

\section{INTRODUCTION}

Ayurveda, the science of life is one of the ancient and comprehensive systems of health care originated in India. The World Health Organization estimates that $70-80 \%$ of people worldwide rely chiefly on traditional, largely herbal medicines to meet their primary health care needs. All medicines, whether synthetic or of plant origin, should fulfil the basic requirements of being safe and effective $[1,2]$. Standardisation of herbal medicines is the process of prescribing a set of standards or inherent characteristics, constant parameters and definitive qualitative and quantitative values that carry an assurance of quality, efficacy, safety, and reproducibility. Maximum classical texts have quoted Veerataru to be effective in the disorders as Vata Roga. And Chirabilva is also indicated in Charaka, Sushrutha classical treatise and other traditional systems for the treatment of Shotha, Amlapitta, Aruchi, Ethiopia, Udarshoola, Krumi,cardio, Switra, Kustha, Shleepada, Madhumeha, Arsha, and Amavata. One of these formulations contains aqueous extract of a combination of stem bark powder of Chirabilva (C) and Veerataru (V) for the management of convulsion. Dichrostachys cinerea belongs to the family Mimosae [3] a subfamily of Leguminosae covering 951 species in India. Dichrostachys cinerea Linn, [4] amongst the one found to be present throughout in India especially in dry areas. It is a shrub or small spiny much branched tree with bipinnate leaves, leaflets linear to oblique, acute, gland-dotted; flowers are hermaphrodite, short dense, axillary spikes with two coloured mainly yellow at the base and white or purple at the top. [5] Holopteleaintegrifolia belongs to the family Ulmaceae, having 15 genera and about 200 species, distributed over tropical and temperate regions of Northern hemisphere including Indian peninsula to Indo-China and Srilanka [6]. It is medium sized to a large glabrous deciduous tree, 15-25 m in height with whitish or yellowish grey bark exfoliating in irregular flakes and with an offensive smell when freshly cut [7]. There is no monograph on the standardisation of Verrataru and although this drug combination explained in Ayurvedic Pharmacopoeia of India (Part IId Formulations). There is no report on the standardisation stem bark of combination as well as the individual respective plant. On the other hand, the natural plants are a complex multicomponent mixture. Their phytochemical composition is not constant because of inherent variability and external influences. Nowadays, various scientific efforts have been made to establish the standards for such type of tribal/evidential claims through modern analytical techniques. The evident folklore claims should be validated and authenticate by using standard scientific methodologies. Contrariwise, natural product extract are a complex mixture that contains various class of compounds. In that circumstances the present study, individual drug along with combination was subjected to morphological and micro-macroscopical, physicochemical, phytochemical and DNA fingerprinting, high-performance thin-layer chromategraphy (HPTLC) study represent the systemic elementary quality control to establish a systemic roadmap for standardisation herbal formulation. This study revealed the conventional analytical approaches along with chromatographic fingerprint technique is focused on the holistic characterization of a complex system by well-known chemometrics method, Principal component analysis. It is useful for botanical or plant identification and authentication of crude plant materials along with mixer as part of an effort and regulator system for standardisation and quality control. 


\section{MATERIALS AND METHODS}

\section{Collection and identification of plant samples}

Stems of Chirabilva (Holopteleaintegrifolia Planch; family-ulmaceae) and Veerataru (Dichrostachys cinerea Linn. family-mimosoideae) were collected of IPGT and RA campus and Raka-Khtia, Jamnagar respectively and subsequently identified and authenticated from Pharmacognosy department (Phm-6186/2016, and Phm$6187 / 2016)$. After proper washing, it was dried under shade at a room temperature for seven days and then grinded with a mechanical grinder. Finally, the coarse powders were separated by sieving using 40 meshes and stored in an airtight container for further use.

\section{Preparation of plant extract}

The individual raw drug powders were passed separately through a sieve (\# 44). Each ingredient was weighed separately and mixed together in the proportion specified; the mixture was passed through sieve number 44 to obtain a homogenous blend and packed in an air-tight container. After that the fresh coarse powders were individually as well as polyherbal formulation subjected to macerated with methanol (Merck, Germany) in a ratio of 1:5. The extracts were filtered and the solvents were evaporated under temperature controlled water bath. The dried extracts were stored in a refrigerator at $4^{\circ} \mathrm{C}$ until further analysis.

\section{Macroscopic analysis}

Natural habitat and morphological character of the respective plants studied under systematic way. Transverse sections of stem bark of both plants were taken and microscopically characters were noted down after proper mounting and staining with the respective specific chemical reagents: lignified cell wall (phloroglucinol/HCl), calcium oxalate (chloral hydrate), starch (N/50 iodine), tannin (ferric chloride) and suberized cell wall (Sudan red TS)[8]. The powder microscopy of the polyherbal containing formulation, for identification, was carried out by following routine procedure. The images were processed using Photoshop imaging system. Consequently, the histochemical analysis was done on the powdered plant materials to observe the presence of certain microscopic structures using above explaining reagent. All slides were deposited in the micro technique of Pharmacognosy laboratory, University Gujarat Ayurveda, Gujarat.

\section{Physicho-chemical analysis and phytochemical analysis}

The moisture, ash, extractive value and other physicho-chemical constant were determined by using Association of Official Analytical Chemist [9]. The the selective phytochemical screening was done according to Harbone [10].

\section{RAPD technique}

Fresh leaves of Chirabilva, Verrataru were used in molecular characterization and DNA fingerprints were obtained by standard and most convenient RAPD method [11] with slight modification. The RAPD reaction was performed with sequential manner DNA isolation, Column purification, lysis buffer and amplification. In brief DNA identification was done using a Pico-drop spectrophotometer and DNA sample was diluted using TE buffer up to $50 \mathrm{ng} / \mathrm{ul}$. The quality of two samples Holopteleaintegrifolia Planch and Dichrostachys cinerea Linn, DNA was checked by 08\% Agarose gel electrophoresis. RAPD-ISSR PCR was carried out in Veriti ABI thermal cycler. Chirabilva and Verrataru leaves showed fingerprinting pattern of selecting primer 1 is on the left most side and primer 12 is on the right side (table 1). The resolved amplification products were visualized by illumination under UV light in Gel document system.

Table 1: List of RAPD primers used for the analysis of two leaves DNA sample

\begin{tabular}{llll}
\hline S. No. & Primer & Sequence 5'-3' & Tm (0C) \\
\hline 1 & OPN-04 & GACCGACCCA & 27.0 \\
2 & OPN-09 & TGCCGGCTTG & 27.0 \\
3 & OPO-07 & CAGCACTGAC & 25.0 \\
4 & OPO-10 & TCAGAGCGCC & 27.0 \\
5 & OPP-08 & ACATCGCCCA & 25.0 \\
6 & OPP-09 & GTGGTCCGCA & 25.0 \\
7 & OPQ-09 & GGCTAACCGA & 25.0 \\
8 & OPR-05 & GACCTAGTGG & 25.0 \\
9 & OPR-06 & GTCTACGGCA & 25.0 \\
10 & OPR-09 & TGAGCACGAG & 25.0 \\
11 & OPS-05 & TTTGGGGCCT & 25.0 \\
12 & OPT-01 & GGGCCACTCA & 25.0 \\
\hline
\end{tabular}

\section{High-performance thin layer chromatographic (HPTLC) profiling}

\section{Sample application}

Band wise with Automatic TLC Sampler, 3 tracks, band length 10 $\mathrm{mm}$, track distance $10 \mathrm{~mm}$, distance from left edge $20 \mathrm{~mm}$, distance from lower edge $8 \mathrm{~mm}$, application volume $7.2 \mu \mathrm{l}$ for an analytical profile of the respective sample.

\section{Chromatography}

In the twin trough chamber saturation (with filter paper) for $20 \mathrm{~min}$ and after plate conditioning at $47 \%$ relative humidity for $10 \mathrm{~min}$ using a solution in methanol, development toluene: chloroform: acetone $(4.2: 5.3: 5 \mathrm{v} / \mathrm{v})$ with up to the migration distance of $80 \mathrm{~mm}$ (from lower plate edge) drying for $5 \mathrm{~min}$.

\section{Documentation}

With the TLC Visualizer under short UV $254 \mathrm{~nm}$ and long UV $366 \mathrm{~nm}$.

\section{Densitometry}

TLC Scanner 3 and win CATS, absorption measurement at 254,366, etc $\mathrm{nm}$, slit dimension $5.00 \times 0.30 \mathrm{~mm}$, scan speed $20 \mathrm{~mm} / \mathrm{s}$, spectra recording from 190 to $780 \mathrm{~nm}$. Also simultaneously densitogramof the experimental plate is taken respected visible range (500-680) $\mathrm{nm}$ at the $20 \mathrm{~nm}$ interval wavelength after vanillin-sulfuric acid visualising agent.

\section{Multivariate analysis}

The search for natural groupings among the samples is a preliminary way to study the chromatography data sets. The chromatographic profiling was subjected to exploratory data analysis, performed by applying principal component analysis (PCA) using Unscrambler ${ }^{\circledR 9.7 ~(C A M O ~ S A, ~} 108$ Oslo, Norway). The entire visible range densitogram is treated as a unique multivariate fingerprint, ie. Multidimensional vector, without identification of special peaks. Principal component analysis uses to discriminate with polyherbal mixer along with respective ingredient.

\section{Data analysis}

In this technique, each sample of the densitogram of respective UVVisible wavelength are taken as a sample, and the whole separation zone is demarcated an arbitrary number designating respective band $(0.1,0.1-0.3,0.5-0.7,0.7-0.9,0.9) \mathrm{R}_{\mathrm{f}}$ as a variable to construct 
the matrix data set. Chemometric tool PCA algorithm was performed by free trial version of "The Unscrambler® 9.7 (CAMO Software AS).

\section{RESULTS AND DISCUSSION}

\section{Macroscopic analysis: anatomical study of the stem}

The observation was made on the stem surfaces of two taxa. The stem bark of $H$. integrifolia is dark brown, cylindrical in shape, woody hard and having longitudinally fissured in fig. (A), while stem bark of $D$. cinerea is light brown in colour, curved, rough, longitudinally grooved and furrowed in fig-(B). Diagrammatic T. S. of the bark Verrataru shows, outermost brown coloured cork, white cortex with groups of stone cells, sclereids and alternate zone of phloem with fibres and medullary rays. Detailed T. S. of bark shows
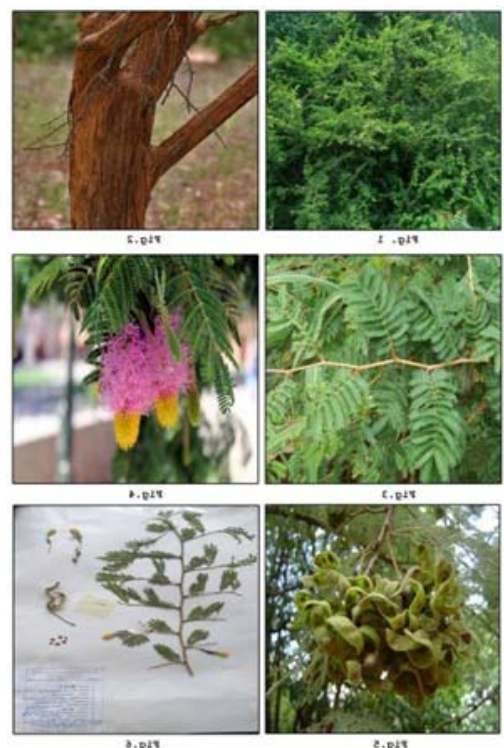

A outermost layers of dark brown coloured cork cells. Cortex is parenchymatous and often observed with scattered groups of stone cells and sclereids. Medullary rays are multiseriate, often longitudinally across the alternate bands of phloem and thick-walled fibres. Prismatic crystals of calcium oxalate and starch grains are found throughout the section in fig-(C). Diagrammatic T. S. of the bark Chirabilva shows an outermost layer of cork cortex, alternate bands of fibres, phloem, and medullary rays. Detailed T. S. of bark shows 10-15 layers of cork filled with brown content at places, followed by a wide zone of cortex made up of spongy parenchyma and alternate bands of phloem and thick walled sclerenchyma fibres and longitudinally running bi-multiseriate medullary rays. Prismatic crystals of calcium oxalate and starch grains are found abundantly throughout the section in fig. (D).
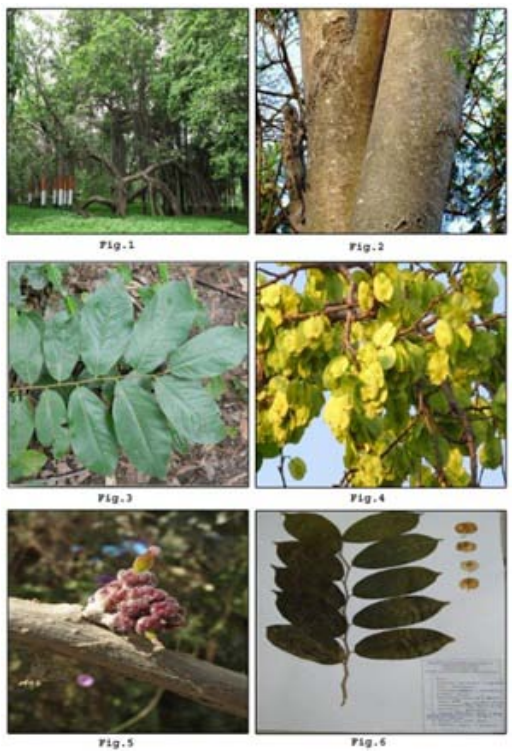

B

Fig. A. Morphological characters of Dichrostachys cinerea Linn. Fig. 1: Plant in its Natural Habitat, fig. 2-Stem bark, fig. 3-Leaf arrangement, fig. 4-Flowers, fig. 5-Fruit, fig. 6-Herbarium of Dichrostachys cinerea Linn, fig. B. Morphological characters of Holoptelea integrin folia planch fig. 1-Plant in its Natural Habitat, fig. 2-Stem bark, fig. 3-Leaf arrangement, fig. 4-Fruits, fig. 5-Flowers, fig. 6-Herbarium of $\boldsymbol{H}$. integrifolia (Roxb.)
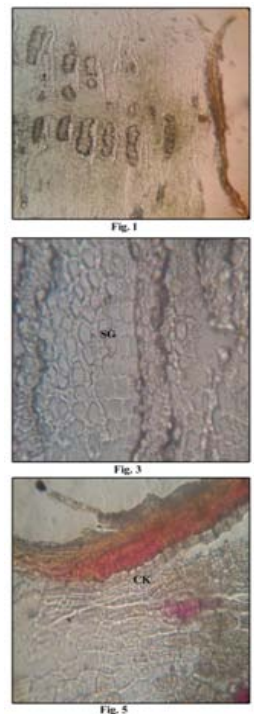

C
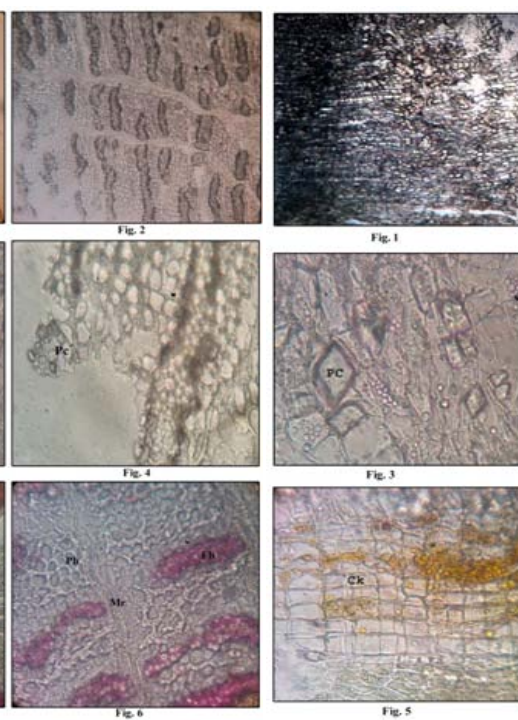

Fies

Fis
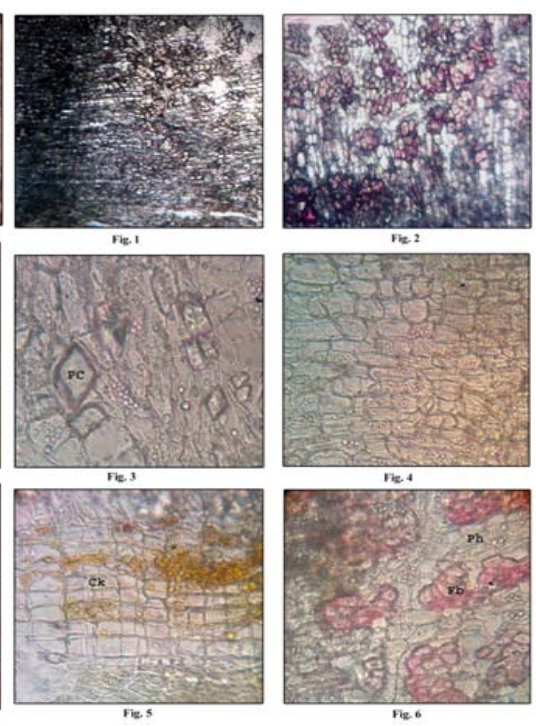

D

Fig. C. T. S. of Veerataru (Dichrostachys cinerea Linn.) stems bark. Fig. 1-Diagrammatic section, fig. 2-Diagrammatic section (stain-1), fig. 3Starch grains, fig. 4-Prismatic crystals, fig. 5-Cork, Cortex, scattered groups of stone cells and sclereids, fig. 6-Alternate layers of phloem and fibres with medullary rays. CK-cork, Fb-fibres, PC-Prismatic crystals, Ph-Phloem, SG-Starch grains,Mr-Medullary rays. Fig. D. T. S. of Chirabilva (Holoptelea integrifolia planch.) stems bark. Fig. 1-Diagrammatic section, fig. 2-Diagrammatic section (stain-1), fig. 3-Prismatic crystals of calcium oxalate, fig. 4-Starch grains, fig. 5-Cork, Cortex Fig. 6-Phloem, fibres with medullary rays 


\section{Powder microscopy}

The diagnostic character of the Chirabilva dried powder microscopy shows presence of Cork in surface view, stone cells, prismatic crystals of calcium oxalate, simple and compound starch grains, yellow content, fibres, crystal fibres, pitted stone cells with wide lumen, fibres passing through medullary rays, lignified fibres, oil globule, and septed fibres in fig. (E). On the Veerataru dried powder microscopy shows the presence of simple fibres, rhomboidal crystals of calcium oxalate, crystal fibres, cork in surface view, fibres passing through medullary rays, simple starch grains, brown content, pitted sclereids, pitted stone cells, normal pitted vessels, lignified fibresin fig. (F).
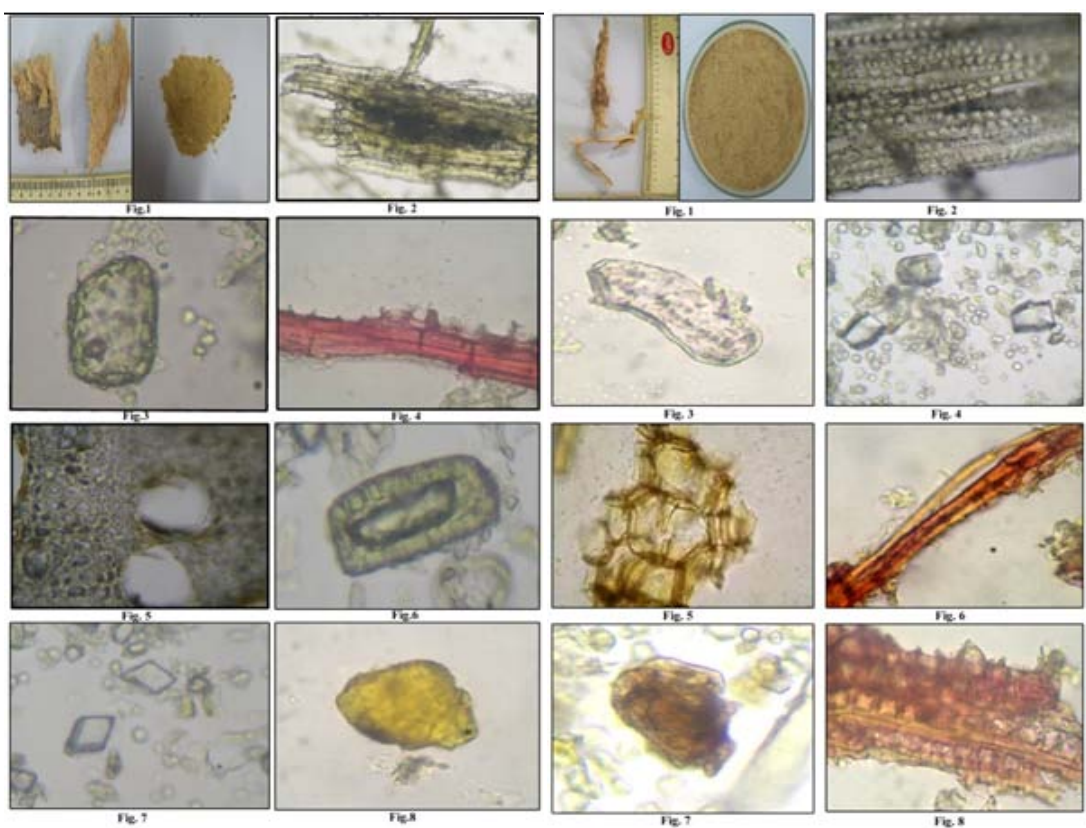

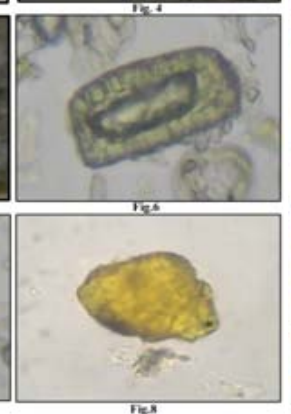

$\mathbf{E}$

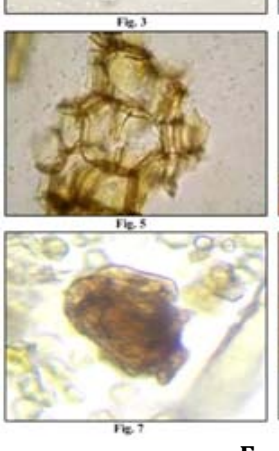

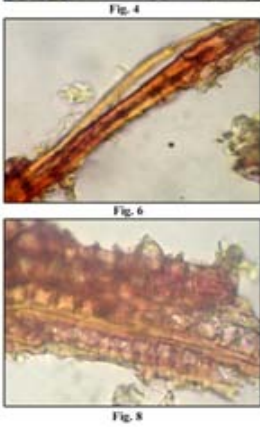

Fig. E. Powder microscopy of Chirabilva stems bark. Fig. 1-Stem bark and stem bark powder, fig. 2-Fibres, fig. 3-Pitted sclereid, fig. 4Lignified fibres, fig. 5-Sectional view, fig. 6-Stone cell, fig. 7-Prismatic crystals, fig. 8-Yellow content. Fig. F. Powder microscopy of Veeratru (Dichrostachys cinerea Linn.) stems bark fig. 1: Stem bark and powder of Veerataru fig. 2: Crystal fibres, fig. 3-Sclereids, fig. 4-Rhomboidal Crystals, fig. 5-Cork in surface view, fig. 6-Medullary rays, fig. 7-Brown content, fig. 8-Lignified crystal fibres

\section{RAPD technique}

Random amplified polymorphic DNA (RAPD) extensively used molecular fingerprinting technique to reveal the genetic diversity among different genotypes. It is very much helpful for genetic uniformity of raw herbal materials. The fingerprinting patterns of Holoptelea integrifolia (Roxb.) Planch and Dichrostachys cinerea Linn samples are seen as vertical columns with horizontal bright and light bands on a dark background have been depicted in the fig. (G) respectively.
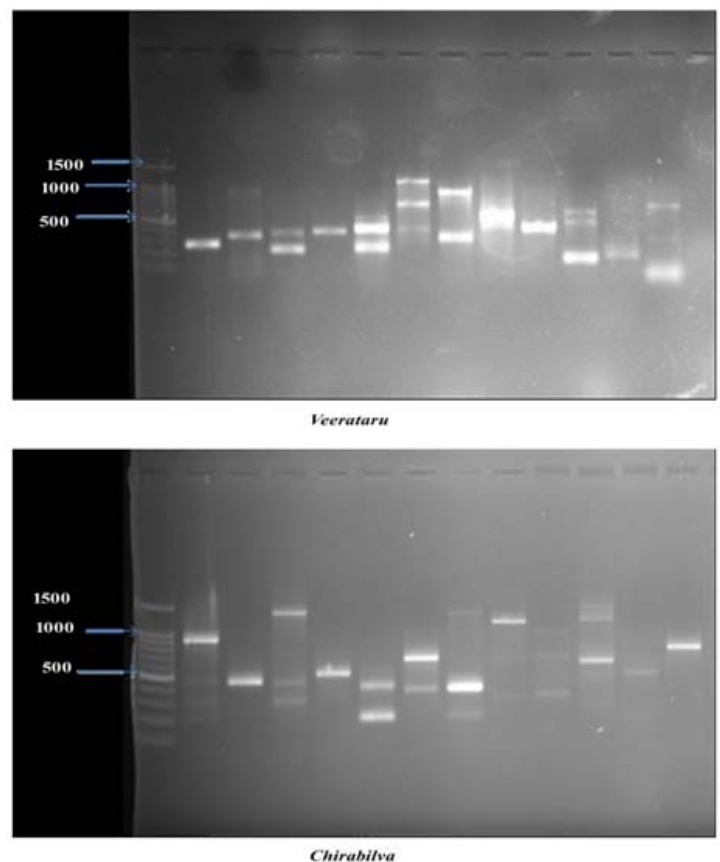

Fig. G: RAPD band pattern of Veerataru and Chirabilva with respect to twelve primers 
All primers showed amplification. In primer 1 range of band size was observed at $200 \mathrm{bpand} 900 \mathrm{bp}$; in primer 2 single band size was observed at $500 \mathrm{bp}$; in primer 3 range of band size was observed from light $300 \mathrm{bp}$ and bright $1400 \mathrm{bp}$; in primer 4 single band size was observed at $500 \mathrm{bp}$; in primer 5 band size was observed at bright $200 \mathrm{bp}$ and at light $450 \mathrm{bp}$; in primer 6 band size was observed at light $400 \mathrm{bp}$ and at bright $700 \mathrm{bp}$; in primer 7 band size was observed at 200bp; at $400 \mathrm{bp}$ and light band around $1500 \mathrm{bp}$; in primer 8 band size was observed at light 300bp and at bright $1200 \mathrm{bp}$; in primer 9 range of light band size was observed from $400 \mathrm{bp}$ to $900 \mathrm{bp}$; in primer range of band size was observed $700 \mathrm{bp}$ to $1500 \mathrm{bp}$; in primer 11 single band size observed at light band $500 \mathrm{bp}$ and in primer 12 single band size observed at $800 \mathrm{bp}$. On the other hand Veerataru leaves showed fingerprinting pattern in favor of primer 1 single band size was observed at $300 \mathrm{bp}$; in primer 2 dark band size was observed at 400bp and light band also observed at $100 \mathrm{bp}, 200 \mathrm{bp}$ and $1000 \mathrm{bp}$; in primer 3 band size was observed at $300 \mathrm{bp}$ and $400 \mathrm{bp}$; in primer 4 single band size was observed at $400 \mathrm{bp}$; in primer 5 band size was observed at $300 \mathrm{bp}$ and at $450 \mathrm{bp}$; in primer 6 range of band size was observed from 450 to $1100 \mathrm{bp}$; in primer 7 band size was observed at $350 \mathrm{bp}$ and at 900 ; in primer 8 single band size was observed at $500 \mathrm{bp}$; in primer 9 single band size was observed at $450 \mathrm{bp}$; in primer 10 band size was observed at $150 \mathrm{bp}$, at $500 \mathrm{bp}$ and at $600 \mathrm{bp}$; in primer 11 single band size observed at $200 \mathrm{bp}$ and in primer 12 band size observed at $100 \mathrm{bp}$ and at $700 \mathrm{bp}$.

\section{Organoleptic study and physicho-chemical constant}

Organoleptic study of the respective sample is depicted in table [2] The physicho-chemical parameters are helpful in judging the purity and quality of the drug. The foreign matters were present in a negligible amount in the formulation. This may be due to the firsthand collection of plant material from the non-polluted area. Loss on drying signifies the considerable amount of moisture; ash values were used to detect the presence of siliceous contamination and water soluble salts. Acid insoluble ash which reveals the possibility of the presence of non-physiological ash. The water and alcohol soluble extractive indicating the percentage of soluble polar and moderatly polar component. The physicho-chemical finding of the polyherbal formulation along with its respective ingredients depicted in table [3].

Table 2: Organoleptic characters of test drugs

\begin{tabular}{llll}
\hline Organoleptic & Stem bark powder of & Stem bark powder & Stem bark powder \\
\hline Character & Chirabilva $(\mathrm{C})$ & Veerataru $(\mathrm{V})$ & of $(\mathrm{C}+\mathrm{V})$ \\
Colour & Yellowish brown & Brown & Light brown \\
Odour & Slightly aromatic & slightly aromatic & Aromatic \\
Touch & Coarse, rough & Coarse, rough, fibrous & Coarse, rough, fibrous \\
\hline
\end{tabular}

Table 3: Physico-chemical constants of raw materials used for the preparation of polyherbal powder

\begin{tabular}{lllllll}
\hline Name of the ingredients & \multicolumn{2}{l}{ Results expressed as \% w/w $\mathbf{~} \mathbf{n}=\mathbf{3})$} & & WSE & ASE \\
\hline & FM & LOD & TA & AIA & $0.25 \pm 0.20$ & $8.08 \pm 0.20$ \\
\hline Veerataru & nil & $5.03 \pm 0.12$ & $12.85 \pm 0.41$ & $3.1 \pm 0.02$ & $10.04 \pm 0.10$ & $12 \pm 0.05$ \\
Chirabilva & nil & $11.05 \pm 0.10$ & $9.05 \pm 0.10$ & $0.45 \pm 0.02$ & $12.5 \pm 0.31$ & $11 \pm 0.10$ \\
Polyherbal mixer & nil & $10.02 \pm 0.12$ & $9.7 \pm 0.10$ & &
\end{tabular}

FM = foreign matter; LOD = loss on drying; TA = total ash; AIA = acid insoluble ash; WSE $=$ water soluble extractive, ASE $=$ alcohol soluble extractive.

\section{Phytochemical analysis}

The preliminary phytochemical screening of polyherbal formulation along with respective ingredient gave the various secondary class of materials (carbohydrate, flavonoids, polyphenol, protein and steroids. The phytochemical finding demarcted in table [4].

\section{Chromatographic analysis}

In this study, a combination of toluene, chloroform and acetone (8:5:7 $\mathrm{v} / \mathrm{v} / \mathrm{v}$ ) as the mobile phase of HPTLC analysis of individual component as well as mixture formulation resulted in well-separated, compact and symmetrical bands. On the other hand, the Chromophores sensitive component indirectly indicates the presence of the functional group in depicted table (5) in terms of applying UV-VIS sensitive detector in instrument HPTLC. HPTLC fingerprint profiles of the above explaining ingredient and poly herbal mixer (CV) methanol extracts are shown in fig. $(H)$. HPTLC fingerprinting profiles $R_{f}$ values in depicted table (6). HPTLC in the methanol extract of all three samples shows maximum resolution insolvent system. Depending on the number of spots, we can depict the number active principle present.

Table 4: Preliminary phytochemical screening of polyherbal extract along with individual ingredient

\begin{tabular}{lll}
\hline Phytochemical screening & Response & \\
\cline { 2 - 3 } & Veerataru & Chirabilva \\
\hline Flavonoid glycosides(Vanillin-HCL test) & Positive & Positive \\
Steroid glycoside (Salkowaski test) & Positive & Positive \\
Phenolic compound (Ammonia, Shinoda) & Positive & Positive \\
Carbohydrate (Molish test) & Positive & Positive \\
Amino acid (Biuret test) & Positive & Positive \\
\hline
\end{tabular}

Table 5: List of uv-vis sensitive compound alignment of registered wavelength [12]

\begin{tabular}{llll}
\hline Chromophore & Transition & Structure & $\lambda$ max \\
\hline Aldehyde & $n-\pi, \pi-\pi^{*}$ & CHO & $280-300$ \\
Carbonyl & $n-\pi$ & C $=0$ & $270-285$ \\
Benzene & $\pi-\pi^{*}$ & Aromatic ring & $204-255$ \\
Anthracene & $\pi-\pi^{*}$ & Fused aromatic ring & 252 \\
Two-conjugated & $\pi-\pi^{*}$ & Crotonaldehyde & $220-322$ \\
\hline
\end{tabular}



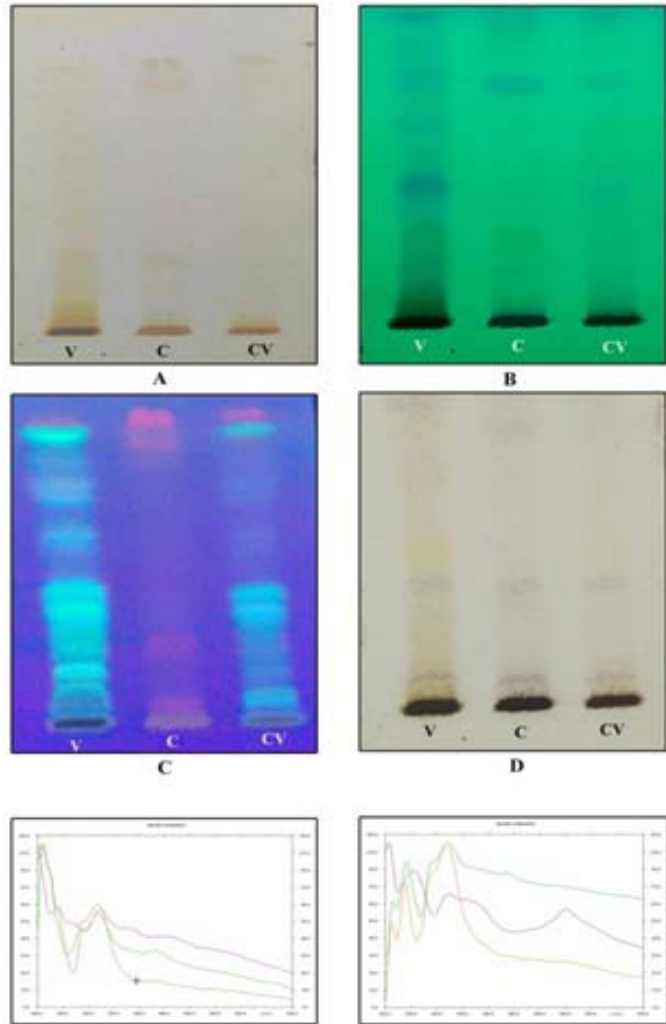

H

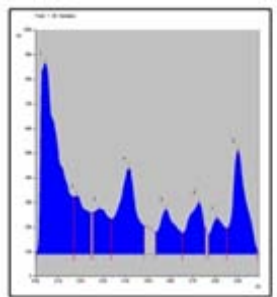

Fig. 1

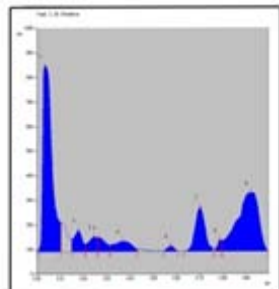

Fig. 2

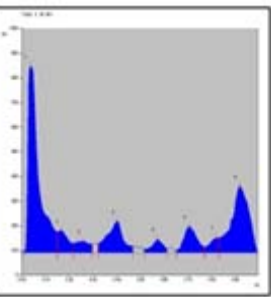

Fig.
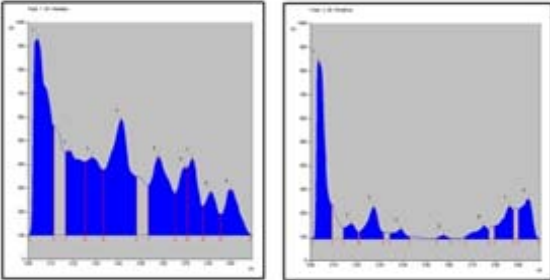

Fig. 5

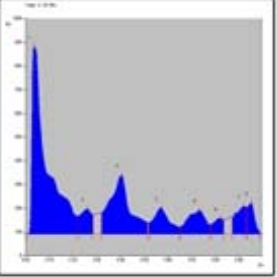

Fig 6
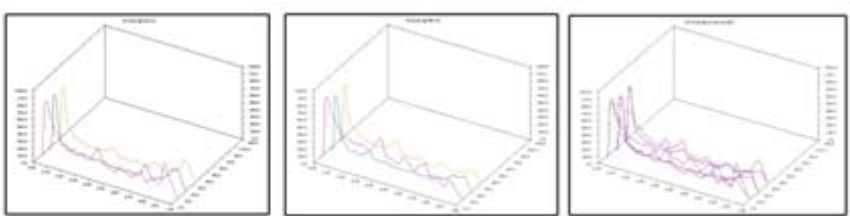

Fiq 7

Fig. 8

Fig 9

Fig. H. Separation of methanol extracted Polyherbal formulation on HPTLC Si $60 \mathrm{~F}_{254}$ with toluene, chloroform, acetone $(8+5+7$, v/v), chamber saturation, stained with the vanillin-sulfuric acid reagent. Tracks: 1. v extract, 2. c extract, 3. cv extract, A-Day light, B-Short UV (254 nm), CLong UV (366 nm), D-After Visualizing agent, $E$ and F spectral comparison of individual ingredient along with polyherbal mixer formulation. Fig. I. HPTLC densitometry chromatogram (at $254 \mathrm{~nm}, 366 \mathrm{~nm}$ ) of methanolic extracts of veertaru, chirabilva, polyherbal mix and 3D densitogram with toluene, chloroform, acetone $(8+5+7, v / v)$ as the mobile phase. Fig. 1, fig. 2,fig. 3, fig. 4, fig. 5, fig. 6,fig. 7, fig. 8,Fig. 9 respectively 


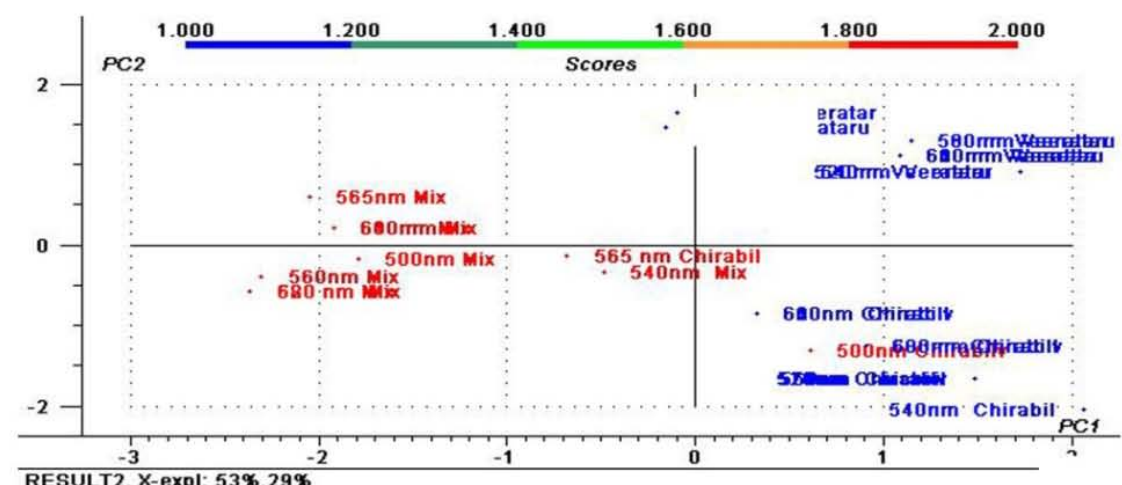

A

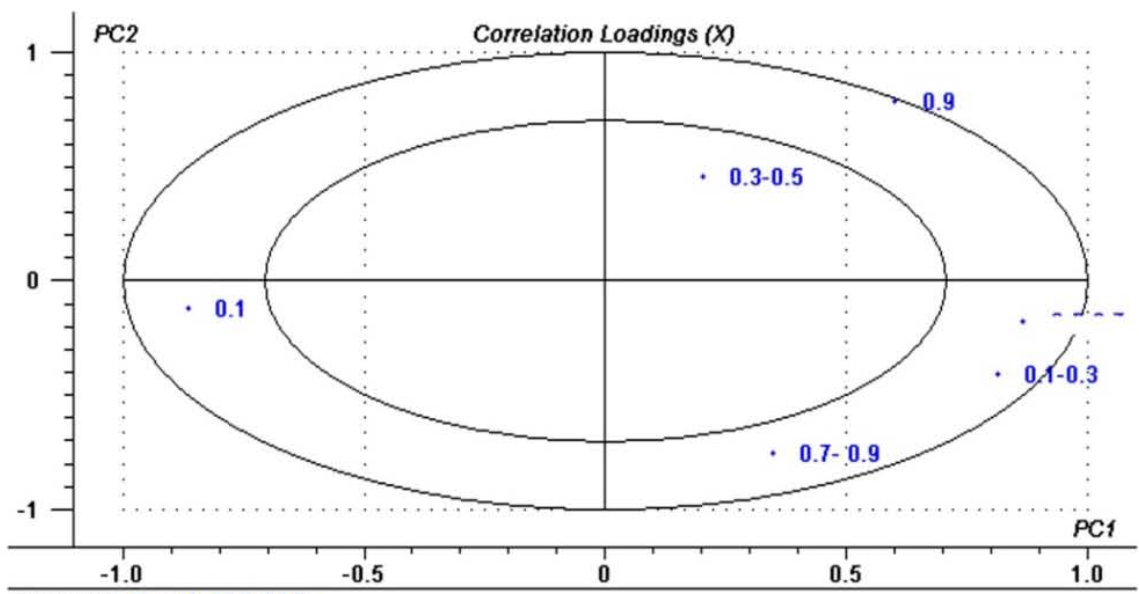

RESULT2, X-expl: 53\%,29\%

B

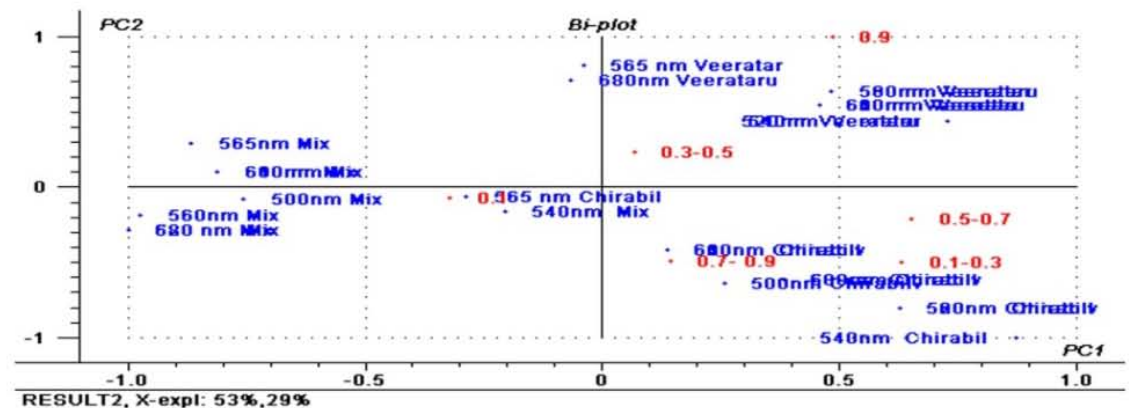

C

Fig. J.(A) PCA score plot and (B) loading plot (C) Bi-plot of three samples based on its chromatographic separation behavior showing the distribution pattern of samples and various $\mathrm{Rf}$ (band) contributing to the groups respectively. The ellipse represents the Hotelling $\mathrm{T} 2$ with $95 \%$ confidence in score plot

\section{Multivariate analysis}

\section{Principal component analysis}

PCA was performed to provide a data structure study in a reduced dimension, covering the maximum amount of information present in the data. It is worth mentioning that PCA is among the most versatile of all chemometric methods as it involves a mathematical procedure that reduces data dimensionality. The data matrix corresponding to the chromatographic data Table-was submitted to PCA in order to show possible trends in their values and emphasise the similarities and differences between samples on a score plot. The score plot in fig. J (A) showed that the authenticated Chirabilva, Veerataru and Mix herbal samples were clearly discriminated in PC1 vs. PC2 space. In the upper left quadrant the mixer adsorption chromatograph profile (after visualization) of the score plot, though some wavelength scanning profile of mixed samples, $500 \mathrm{~nm}, 540 \mathrm{~nm}, 560$ $\mathrm{nm}$ and $580 \mathrm{~nm}$ appear below the horizontal line of the score plot. Authentified Chirabilva samples were well separated from the mixer samples scattered in the lower right quadrant except for $565 \mathrm{~nm}$ mix which appeared the lower left quadrant. However, the sample Veerataru were scattered upper right quadrant. From the loading plot in fig. J (B), it appeared that the 0.1,0.1-0.3, 0.3-0.5, 0.5-0.7, 0.9 separating chromatographic bands contributing to the grouping of experimental samples, and that these attributes corresponded to the PC1 and PC2 which explained about $74 \%$ of the total variance. It should be noted that genuine mix samples are differentiated from other samples by decrease their no of spot in 0.5-0.7 RF (band) region with respect to Chirabilva and Veerataru. 
Table 6: Chromatographic data table of respective sample of registered wavelength

\begin{tabular}{|c|c|c|c|c|c|c|c|}
\hline Wave length & Sample & less than 0.1 & $0.1-0.3$ & $0.3-0.5$ & $0.5-0.7$ & $0.7-0.9$ & More than 0.9 \\
\hline \multirow[t]{3}{*}{$254 \mathrm{~nm}$} & Veerataru & 1 & 2 & 1 & 1 & 3 & 0 \\
\hline & Chirabilva & 1 & 3 & 1 & 2 & 1 & 1 \\
\hline & Mixture & 1 & 2 & 1 & 1 & 2 & 1 \\
\hline \multirow[t]{3}{*}{$366 \mathrm{~nm}$} & Veerataru & 1 & 2 & 1 & 2 & 3 & 0 \\
\hline & Chirabilva & 1 & 2 & 1 & 1 & 2 & 1 \\
\hline & Mixture & 1 & 1 & 1 & 1 & 2 & 2 \\
\hline \multirow[t]{3}{*}{$500 \mathrm{~nm}$} & Veerataru & 1 & 1 & 2 & 1 & 3 & 3 \\
\hline & Chirabilva & 2 & 2 & 1 & 1 & 4 & 1 \\
\hline & Mixture & 2 & 0 & 1 & 0 & 4 & 1 \\
\hline \multirow[t]{3}{*}{$520 \mathrm{~nm}$} & Veerataru & 1 & 2 & 2 & 1 & 3 & 3 \\
\hline & Chirabilva & 1 & 3 & 1 & 1 & 4 & 1 \\
\hline & Mixture & 1 & 1 & 2 & 1 & 4 & 1 \\
\hline \multirow[t]{3}{*}{$540 \mathrm{~nm}$} & Veerataru & 1 & 2 & 2 & 1 & 3 & 3 \\
\hline & Chirabilva & 1 & 4 & 1 & 1 & 4 & 1 \\
\hline & Mixture & 2 & 0 & 2 & 1 & 4 & 1 \\
\hline \multirow[t]{3}{*}{$560 \mathrm{~nm}$} & Veerataru & 1 & 1 & 2 & 1 & 3 & 3 \\
\hline & Chirabilva & 1 & 3 & 1 & 1 & 4 & 1 \\
\hline & Mixture & 2 & 0 & 2 & 0 & 3 & 0 \\
\hline \multirow[t]{3}{*}{$565 \mathrm{~nm}$} & Veerataru & 1 & 1 & 2 & 0 & 3 & 3 \\
\hline & Chirabilva & 2 & 0 & 1 & 1 & 3 & 1 \\
\hline & Mixture & 2 & 0 & 1 & 0 & 2 & 1 \\
\hline \multirow[t]{3}{*}{$580 \mathrm{~nm}$} & Veerataru & 1 & 1 & 2 & 1 & 3 & 3 \\
\hline & Chirabilva & 1 & 2 & 1 & 1 & 4 & 1 \\
\hline & Mixture & 2 & 0 & 1 & 0 & 3 & \\
\hline \multirow[t]{3}{*}{$600 \mathrm{~nm}$} & Veerataru & 1 & 1 & 1 & 1 & 3 & 3 \\
\hline & Chirabilva & 1 & 2 & 1 & 1 & 4 & 1 \\
\hline & Mixture & 2 & 0 & 1 & 0 & 3 & 1 \\
\hline \multirow[t]{3}{*}{$620 \mathrm{~nm}$} & Veerataru & 1 & 1 & 1 & 1 & 3 & 3 \\
\hline & Chirabilva & 1 & 1 & 1 & 1 & 4 & 1 \\
\hline & Mixture & 2 & 0 & 1 & 0 & 3 & 0 \\
\hline \multirow[t]{3}{*}{$640 \mathrm{~nm}$} & Veerataru & 1 & 1 & 1 & 1 & 3 & 3 \\
\hline & Chirabilva & 1 & 1 & 1 & 1 & 4 & 1 \\
\hline & Mixture & 2 & 0 & 1 & 0 & 3 & 1 \\
\hline \multirow[t]{3}{*}{$660 \mathrm{~nm}$} & Veerataru & 1 & 1 & 1 & 1 & 3 & 3 \\
\hline & Chirabilva & 1 & 1 & 1 & 1 & 4 & 1 \\
\hline & Mixture & 2 & 0 & 1 & 0 & 3 & 1 \\
\hline \multirow[t]{3}{*}{$680 \mathrm{~nm}$} & Veerataru & 1 & 1 & 1 & 0 & 3 & 3 \\
\hline & Chirabilva & 1 & 1 & 1 & 1 & 4 & 1 \\
\hline & Mixture & 2 & 0 & 1 & 0 & 3 & 1 \\
\hline
\end{tabular}

\section{CONCLUSION}

Results from this study provide important information and data for systematic and authentication of the stem bark of Dichrostachyscinerea and Holoptelea integrifoila. Transverse section of the fresh plant material would give the most accurate identification of the two representative ingredients of polyherbal mixer formulation based on their characteristic differences of anatomical features in terms of the type of crock, stone cell, prismatic and calcium oxalate crystal. The powder microscopic character is easily identified by their characteristic feature. The RAPD analysis of Dichrostachyscinerea and Holoptelea integrifolia showed some similar bands at the same wavelength indicate the presence of the similar chemical moieties may take into consideration of genetically identically fingerprinting. The physicochemical constant and phytochemical screening showed purity, identity and presence of a various class of moiety respectively. However, HPTLC technique could be utilised to distinguish the powders of three different classes based on the presence or absence of certain target phytochemical (flavonoid, polyphenol, etc) constituents, manifested as peaks or bands from the chemical fingerprint profiles. The samples are discriminated after visualising agent due to various concentration levels of class materials. Similar because of the virtue of co-solubility of various secondary plant metabolite. Proper identification and authentication of raw plant materials to be used in the polyherbal evident based mixer would ensure well-defined and consistent quality, safety and efficacy of herbal preparation and products.

\section{Author's contribution}

Hetal is MD. A candidate who conducted the experimental work. Jayanta Kumar Maji is the project leader responsible for the research design and drafting and editing of the manuscript. Harish sir helped with the microscopic analysis and reviewed the microscopic section of the manuscript. JKMAJI provided technical assistance physicochemical, phytochemical and chromatographic experiments. All authors have read the final draft and approve submission of the manuscript.

\section{ACKNOWLEDGEMENT}

The authors thank the Gujarat Ayurveda University for the financial support.

\section{CONFLICT OF INTERESTS}

The authors declare no conflicts of interest

\section{REFERENCES}

1. Mosihuzzaman M, Choudhary MI. Protocols on safety, efficacy, standardisation, and documentation of herbal medicine (IUPAC Technical Report). Pure Appl Chem 2008;80:2195-30.

2. Folashade O, Omoregie H, Ochogu P. Standardization of herbal medicines-A review. Int $\mathrm{J}$ Biodiversity Conservation 2012;4:101-12.

3. Patel VB, Kevalia J, Sharma PP. Pharmacognostical evaluation of veerataru-dichrostachys cinerea linn. Mimosae (Leguminosae). Pharma Sci Monit 2013;4:3446-54.

4. Sind WA. Talbots. Forest Flora of Bombay Presidensy. In: MS Bishen Singh, Mahendra Pal Singh. editor. Vol. I. Popular Publisher; 1976. p. 473.

5. A wealth of India. Council of Scientific and Industrial Research, New Delhi, reprint; 2003. p. 174-5. 
6. Mahmud S, Shareef H, Ahmad M, Gouhar S, Rizwani GH. Pharmacognostic studies on fresh mature leaves of Holoptelea Integrifolia (Roxb.) Planch. Pakistan J Bot 2010;42:3705-8.

7. Anonymous: The useful plants of India, Council of Scientific and Industrial Research, New Delhi, Publication and Information Directorate, CSIR; 1992. p. 271, 622.

8. TE Wallis. Chap no XXII. In: TE Wallis. editor. Textbook of Pharmacognosy. 5th ed. CBS Publisher; 1998. p. 578.

9. Official Methods of Analysis. 15th Edn. Association of Official Analytical Chemists. Washington DC. USA; 1990.

10. Harbone JB. Phytochemical methods a guide to modern techniques of plant analysis. In: Harbone. editor. $3^{\text {rd }}$ edition. London: Champman and Hall Publishers; 1998. p. 91-2.
11. Bharmauria V, Narang N, Verma V, Sharma S. Genetic variation and polymorphism in the Himalayan nettle plant Urticadioicabased on RAPD marker. J Med Plant Res 2009;3:166-70.

12. Absorption spectroscopy: Kenneth A, Connors. A Textbook of Pharmaceutical of Pharmaceutical Analysis. 3rd edition. India: Replica Press; 2004. p. 173-206.

\section{How to cite this article}

- Jayanta Kumar Maji, Hetal Janani, Bhupesh Patel. Standardisation of the anticonvulsant polyherbal formulation by pharmacognostical, DNA fingerprinting and highperformance thin layer chromatography combined with chemometrics. Int J Curr Pharm Res 2017;9(1):50-58. 